Technological University Dublin

DÜBLIN

ARROW@TU Dublin

\title{
The Mainstream Scientific Community is Open to Incremental But Not Holistic Ideas
}

Maurice Goodman

Technological University Dublin, maurice.goodman@tudublin.ie

Follow this and additional works at: https://arrow.tudublin.ie/scschphyart

Part of the Physics Commons

\section{Recommended Citation}

Goodman, M. (2017). The mainstream scientific community is open to incremental but not holistics ideas. NeuroQuantology, 15(2), pp.215-216. doi: 10.14704/nq.2017.15.2.1041

This Article is brought to you for free and open access by the School of Physics \& Clinical \& Optometric Science at ARROW@TU Dublin. It has been accepted for inclusion in Articles by an authorized administrator of ARROW@TU Dublin. For more information, please contact arrow.admin@tudublin.ie, aisling.coyne@tudublin.ie, gerard.connolly@tudublin.ie.

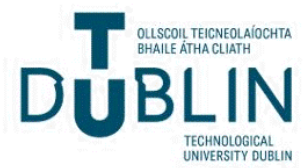




\section{The Mainstream Scientific Community is Open to Incremental but not Holistic Ideas}

\section{Maurice Goodman}

DOI Number: 10.14704/nq.2017.15.2.1041

NeuroQuantology 2017; 2: 215-216

\section{Introduction}

I agree with the view expressed, in your editorial in the March 2017 issue of NeuroQuantology, that we need to be brave enough to rewrite and most likely add to the physics text books if we are to make progress in consciousness and the workings of the mind. The question is, what do we need to add? The good news is that this will not require any new revolution, but a full acceptance that man is not at the centre of the Universe and all that this implies. The bad news is that our behaviour in the 500 years since Copernicus is possibly one of the worst examples, in history, of man's 'resistance to change'. It is the mainstream scientific community, still subconsciously rooted in pre-Copernican intuitions, that is preventing progress in the fundamental physics of life and hence in fields such as the mind and consciousness.

The mainstream physics community has nothing to say about the fundamental physics (not chemistry) of life and therefore has little or nothing to say about the mind or consciousness. This, I agree, is bad for the image of physics. The negative image relates to how little physics has achieved in a practical sense in the last 100 years. We still call what was done at the end of the $19^{\text {th }}$ and the beginning of the $20^{\text {th }}$ century 'Modern Physics'. In the meantime, physics has contented itself with the esoteric and largely irrelevant fields you mention from M-theory to Theories of

Corresponding author: Maurice Goodman

Address: School of Physics, Dublin Institute of Technology, Dublin 8, Ireland.

e-mail $\square$ maurice.goodman@dit.ie
Everything that have little experimental support. We cannot even say if consciousness has a physical basis or not as we are unable to measure physical content with sufficient accuracy. For example, as was proposed last March 2016 in this Journal (Goodman, 2016), consciousness consisted of the exchange of neutrinos between atomic nuclei and there was one extra neutrino for every atomic nucleus in the brain the total mass of consciousness would be $\sim 1 \%$ of the mass of a single cell in the body. This could not be measured with current technology. Also, as with all complex systems, a single cell must have an instantaneous, long range (cellular distances) secure communication system to prevent a decent into chaos. Given that we do not know how this is achieved in the cell we are hopelessly ill-equipped to understand multi-cellular structures such as the brain or add anything new to the physics textbooks to help understand how a single cell functions never mind build a science of consciousness. A holistic approach is needed to see how we might change this state of affairs.

The proof that man is not at the centre of the universe is everywhere. The latest evidence is that there are billions of Earth like planets orbiting sun like stars at the appropriate distance for life to exist throughout the entire cosmos. There is nothing unique about where we live. This in turn implies that Earth Science is not a fundamental 
natural science and should be treated as an interdisciplinary sub-field of those that are. Also, in natural science the separation of Biology from the other physical sciences is without foundation and is completely arbitrary. All biological structures are made of physical matter. The mainstream scientific community, for the last 30 years, have been unwilling to allow a discussion, about the evidence for these views, to take place. This lack of leadership must stop and the community, as you say, must show courage and pursue the truth irrespective of the beliefs it undermines as beliefs are motivated by emotion and are not rational. Also, attempting to place consciousness as central to the measurement problem in quantum mechanics in no way undoes what Copernicus discovered and it is our responsibility to fully accept this. The rules of quantum mechanics had long since dictated the arrangement of atomic nuclei, atoms, molecules, planets and stars long before multi-celled creatures and consciousness appeared on earth. After 500 years, it is time that mankind grew up and got over the disillusion associated with the insignificance of our position in the universe.

I see no problem with the fields of parapsychology, or consciousness being ignored or for them to remain unpublished in influential journals, now. Also, new ideas should be poorly funded until they have proved they have some worth. This, on the face of it, may seem harsh. However, if the edifice of science needed to understand and explain the mind were compared to a multi-story building, parapsychology and consciousness are on the top floor with no scientific support from the multiple stories beneath and no chance of a scientific explanation soon. The scientific foundation of that building has yet to be built. On the other hand, it is alarming to observe the mainstream scientific community do nothing to begin to collect, discuss and disseminate ideas from which we might begin to build the foundation and the subsequent floors of this edifice. The objective, in the long run, will be to provide the scientific support needed for areas related to the mind and consciousness. This lack of effort by the mainstream scientific community, in my view, is tantamount to a dereliction of duty. My 30 years of experience has been identical to the parapsychologists. During that time, my ideas on earth science and the fundamental physical underpinning of life have been dismissed by the top science journals without a reason been given. As stated previously the mainstream scientific community is unwilling to consider the evidence for a demotion of earth science or a physical biology. These ideas have been, on countless occasions, shunned by all modes of publicity (conferences, journals etc.) normally open to a scientist, without a valid reason been given. PreCopernican intuitions still rule the roost. My experience is that if you submit a finding that is at odds with the 'status quo' with a negative impact on funding for that field the objectivity of the editors and reviewers fly out the window. (Goodman, 2016).

I believe a rude awakening is on the cards for the mainstream scientific community when the mass of the neutrino is found. The rudeness of the awakening only relates to the inattention of the mainstream for several decades, if not centuries. The first question that will be asked, when the neutrino mass is measured, will be how has nature made use of a mass whose uncertainty in position is the same size as a typical plant or animal cell? The answer is already known. It is evident in material self-organisation on the microscopic scale and the truly spectacular answer of life itself. I believe nature has made use of the electron neutrino to create the almost instantaneous, long range, secure (quantum) communication system needed for the survival of the cell (Goodman, 2015). It may be the case that I will have to wait patiently, as I have for the last 30 years, until the mainstream wakes up and is brave enough to seek the truth. Until then the path to a fundamental physics of biology, mind and consciousness remains closed. It may even be the case that this is how science progresses. Not by a continual series of incremental steps but by, what in future history will be portrayed as, an unheralded discontinuous leap.

\section{References}

Goodman M. A quantum theory of consciousness may require a paradigm shift in biology. Journal of Consciousness Exploration \& Research 2015; 6 (1): 1- 9.

Goodman M. Supressed intuitions, large number coincidences, and a mathematical foundation for life and consciousness. NeuroQuantology 2016; 14(1): 62-67.

Goodman M. Where peer review fails. (Feedback) Physics World, March 2016, Vol 29, No 3, pp 21-22. 